\title{
Type A Wolff-Parkinson-White syndrome obscured by left bundle branch block associated with a vascular malformation of the coronary sinus
}

\author{
KILLIAN ROBINSON, MICHAEL J DAVIES, * DENNIS M KRIKLER \\ From the Division of Cardiovascular Disease, Hammersmith Hospital, and the ${ }^{\star D e p a r t m e n t ~ o f ~ C a r d i o v a s c u l a r ~}$ \\ Pathology, St George's Hospital, London
}

SUMmarY A case of Wolff-Parkinson-White syndrome type A with coexisting ipsilateral bundle branch block is presented. The diagnosis was suspected because of subtle electrocardiographic changes and was confirmed at electrophysiological study. Necropsy showed a vascular anomaly of the coronary sinus that contained bundles of myocardial muscle which crossed the atrioventricular ring at a site that was consistent with the predicted accessory pathway.

In the Wolff-Parkinson-White syndrome the diagnosis of coexisting bundle branch block may be obscured by the presence of an accessory pathway on the same side of the heart.' We report a case of WolffParkinson-White syndrome in which a left sided accessory pathway was confirmed at necropsy in a patient known to have left bundle branch block.

\section{Case report}

A 66 year old woman was studied because she had recurrent episodes of paroxysmal supraventricular tachycardia that were resistant to conventional medical management because of coexistent sinus node disease. ${ }^{2}$ A dual demand pacemaker designed to switch into a fixed rate mode at 70 beats/min when the heart rate exceeded 150 was successfully implanted and controlled the arrhythmia. The electrocardiographic and electrophysiological studies were reported in detail elsewhere. ${ }^{2-}$

The resting electrocardiograms at the time of presentation had shown the appearance in fig la and she was referred with the diagnosis of WolffParkinson-White syndrome type $B$. The configuration of left bundle branch block was seen in escape complexes $^{3}$ (fig 1b) and during orthodromic tachycardia (fig 1c); the features of the Wolff-Parkinson-White syndrome type $A$ were seen on one

Requests for reprints to Dr Dennis M Krikler, Division of Cardiovascular Disease, Royal Postgraduate Medical School, Hammersmith Hospital, Ducane Road, London W12 0HS. occasion, immediately after conversion to sinus rhythm by intravenous verapamil (fig 1d).

At electrophysiological study orthodromic reciprocating atrioventricular tachycardia with left bundle branch block configuration was initiated by premature right atrial extrastimuli. The earliest retrograde activation was seen in the left pulmonary artery indicating the presence of a left sided accessory atrioventricular pathway. Sinus node recovery was prolonged and episodes of tachycardia were frequently initiated by $\mathrm{His}$ escapes after sinus pauses. ${ }^{2} \mathrm{~A}$

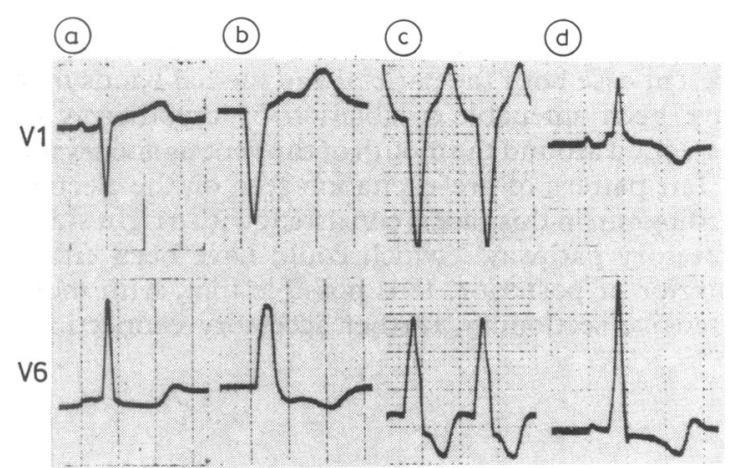

Fig 1 Electrocardiograms (V1 and V6) showing (a) sinus rhythm, (b) junctional escape beats with left bundle branch block, (c) paroxysmal tachycardia (orthodromic) with left bundle branch block, and (d) sinus rhythm with positive delta waves and tall $R$ waves in both leads after termination of tachycardia with verapamil. (Reproduced with permission from Krikler et al ${ }^{4}$.) 
mercury-zinc pulse generator was replaced after two years by one that used a lithium iodide battery; this continued to function until her death 11 years later.

At the age of 79 she complained of recurrent palpitation which was controlled by amiodarone. Several months later she was admitted to another hospital with acute chest pain; myocardial infarction was suspected and she died suddenly.

Necropsy showed acute anteroseptal myocardial infarction with diffuse atherosclerosis causing considerable stenoses of all three major coronary arteries; the heart had already been dissected by the coroner's pathologist. A vascular abnormality (fig 2), consisting of a mass of large dilated veins, was found on the posterior wall of the left ventricle. It drained directly into the coronary sinus. The muscle bundles around these vessels crossed the atrioventricular ring. At the apex of the muscular interventricular septum there was pronounced sclerotic fibrosis associated with total loss of the proximal portion of the left bundle branch and severe loss of conduction fibres in the adjacent bifurcating atrioventricular bundle. Elsewhere the muscular interventricular septum showed old ischaemic scarring. The morbid anatomical changes were those of bundle branch fibrosis as described by Lev. ${ }^{5}$ The sinoatrial node showed almost total non-specific loss of specialised myocytes with a normal nodal artery.

The electrocardiograms at the time of her final admission were incomplete and no conclusions could be drawn about the effect of the acute ischaemic episode on the patterns of the pre-existing conduction abnormalities.

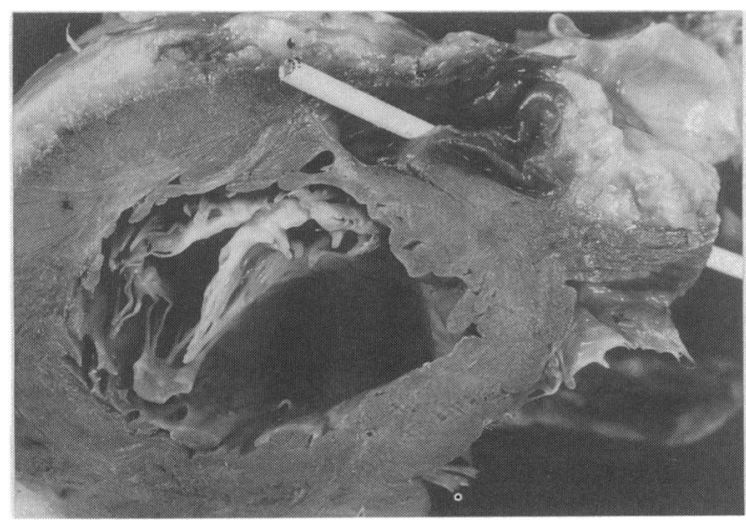

Fig 2 Short axis view of the left ventricle at the level of the mitral valve. The probe is in the coronary sinus and enters a large vascular anomaly behind the left ventricle.

\section{Discussion}

Although there are several reports of the coexistence of left bundle branch block with a left sided accessory pathway, ${ }^{16}$ anatomical confirmation has been lacking. To our knowledge this is the only report of coexisting Wolff-Parkinson-White syndrome and ipsilateral bundle branch block that was suspected on the electrocardiogram, diagnosed at electrophysiological study, and confirmed anatomically.

Because of the coexisting sinus node disease and the complex pattern of pre-excitation a dual demand pacemaker was implanted. This lasted well and required only one change of pulse generator.

In the last year of her life, however, she complained of more frequent episodes of tachycardia, during which the pacemaker did not respond appropriately. This was related to spontaneous prolongation of the arrhythmia cycle length by about $70 \mathrm{~ms}$ resulting in a tachycardia rate of $125 / \mathrm{min}$ that failed to trigger the fixed rate mode and thus terminate the arrhythmia.

During the original electrophysiological study the left bundle branch block could be dissipated by a stimulus strong enough to enter the distal left bundle, implying a discrete, rather than a diffuse, lesion of that branch of the conducting system. ${ }^{2}$ This prediction was confirmed at necropsy. When the accessory pathway is found on the same side as the bundle branch block the absence of the pattern of the bundle branch block suggests that discrete interruptions, rather than diffuse disease, may be most often responsible for disturbances of the conduction system in patients with the pre-excitation syndrome.

The vascular lesion present near the coronary sinus contained muscle fibres in the subpericardial wall, which formed the accessory connection between atrium and ventricle. Detailed anatomical studies of the Wolff-Parkinson-White syndrome are still rare but there is a report of a vascular anomaly of the cardiac venous system that drains into the coronary sinus. ${ }^{7}$ This established an anomalous connection because it contained an outer layer of myocardial tissue that crossed the atrioventricular ring. ${ }^{7}$ Surgeons too have reported finding such abnormalities during the course of division of accessory pathways, ${ }^{8}$ and because of the complications they can cause the possibility that they are present should always be borne in mind whenever an operation or endocavitary ablation is planned.

This unusual type of accessory atrioventricular connection could not be inferred from the clinical and electrocardiographic features. The present patient did, however, illustrate the value of careful analysis of the electrocardiogram in predicting complex lesions that were corroborated by electrophysiological studies and confirmed at necropsy. 


\section{References}

1 Pick A, Fisch C. Ventricular pre-excitation (WPW) in the presence of bundle branch block. Am Heart J 1958;55:504-12.

2 Coumel P, Attuel P, Slama R, Curry P, Krikler D. 'Incessant' tachycardias in Wolff-Parkinson-White syndrome. II. Role of atypical cycle length dependency and nodal-His escape beats in initiating reciprocating tachycardias. $\mathrm{Br}$ Heart $J$ 1976;38: 897-905.

3 Krikler D, Curry P, Buffet J. Dual-demand pacing for reciprocating atrioventricular tachycardia. $\mathrm{Br}$ Med J 1976;i:1114-6.

4 Krikler DM, Coumel P, Curry P, Oakley CM. WolffParkinson-White syndrome type $A$ obscured by left bundle branch block. Eur J Cardiol 1977;5:49-62.

5 Lev M. Complete left bundle branch block: $a$. physiologic-pathologic correlation. Report of a case. $\overrightarrow{\bar{N}}$ Am Heart J 1961;61:149-55.

6 Denes P, Goldfinger P, Rosen KM. Left bundle branch block and intermittent type $A$ pre-excitation. Chest 1969;68:356-8.

7 Gerlis LM, Davies MJ, Boyle R, Williams G, Scott H. Pre-excitation due to accessory sinoventricular connexions associated with coronary sinus aneurysms: a report of two cases. Br Heart J 1985;53:314-22.

8 Guiraudon GM, Klein GJ, Sharma AD, Milstein $S, \overrightarrow{\vec{\omega}}$ McLellan D. Closed heart technique for Wolff-Parkinson-White syndrome: further experience and potential limitations. Ann Thorac Surg 1986;42: 651-7. 